\title{
SEMI-OTOMATIS SISTEM PENGEREMAN AUTONOMOUS VEHICLE MENGGUNAKAN PNEUMATIK SILINDER BERBASIS MIKROKOTROLLER
}

\author{
Teguh Arifianto $\left.{ }^{1}\right)^{*}$, Royyan Ghozali $^{2)}$, Akhwan $^{3)}$, Sunardi $^{4)}$, Willy Artha Wirawan ${ }^{5)}$ \\ Email: teguh@ppi.ac.id ${ }^{1)^{*}}$, royyan.tep1818@taruna.api.ac.id ${ }^{2)}$, akhwan@ppi.ac.id ${ }^{3)}$, \\ sunardi@ppi.ac.id ${ }^{4)}$,willy@pengajar.ppi.ac.id ${ }^{5)}$ \\ 1,2,3,4) Program Studi Teknologi Elektro Perkeretaapian, Politeknik Perkeretaapian Indonesia Madiun \\ 5) Program Studi Teknologi Mekanika Perkeretaapian, Politeknik Perkeretaapian Indonesia Madiun \\ Jl. Tirta Raya, Pojok, Nambangan Lor, Kec. Manguharjo, Madiun, Jawa Timur 63161
}

\begin{abstract}
ABSTRAK
Autonomous vehicle merupakan moda transportasi masa depan yang menerapkan image processing dan computer vision untuk pengenalan objek maupun kendali pada motor. Transportasi ini dapat beroperasi sendiri sehingga kendaraan ini mengutamakan keamanan dalam berkendara. Jika pada kendaraan konvensional, sistem pengereman dikendalikan oleh pengendara. Namun, pada kendaraan autonomous, sistem pengereman akan bekerja pada keadaan tertentu. Penelitian ini memodifikasi pengereman mekanik yang ada pada kendaraan autonomous agar dapat bekerja secara semi otomatis dengan menggunakan aktuator pneumatik silinder berukuran 50x50mm. Selain itu, penelitian ini juga menggunakan sensor warna pixycam dan micro lidar vl5310x sebagai input pada mikrokontroller arduino. Input pada mikrokontroller arduino ini menjadi parameter perintah untuk mengaktifkan selenoid valve agar udara bertekenan dapat menggerakkan pneumatik silinder. Hasil dari penelitian ini adalah pemakaian silinder pneumatik berukuran 50x50mm dapat menarik pedal rem pada sarana autonomous dengan tangki udara bervolume $0,16 \mathrm{~m}^{3}$ dan tekanan sebesar 6 bar.
\end{abstract}

Kata kunci: autonomous vehicle, pengereman, semi otomatis, mikrokontroller, pneumatik.

\section{ABSTRACT}

Autonomous vehicle is a future mode of transportation that applies image processing and computer vision for object recognition and motor control. This transportation can operate alone so this vehicle prioritizes safety in driving. If on a conventional vehicle, the braking system is controlled by the driver. However, in autonomous vehicles, the braking system will work in certain circumstances. This study modifies the existing mechanical braking on autonomous vehicles so that they can work semi-automatically using a cylinder pneumatic actuator measuring 50x50mm. In addition, this study also uses the pixycam color sensor and micro lidar vl53l0x as input to the arduino microcontroller. The input to the Arduino microcontroller is a command parameter to activate the solenoid valve so that compressed air can move the pneumatic cylinder. The result of this research is the use of a pneumatic cylinder measuring $50 x 50 \mathrm{~mm}$ can pull the brake pedal on an autonomous means with an air tank with a volume of $0,16 \mathrm{~m}^{3}$ and a pressure of 6 bar.

Keywords: autonomous vehicle, braking, semi-automatic, microcontroller, pneumatic. 


\section{PENDAHULUAN}

Autonomous vehicle adalah salah satu moda transportasi kendaraan cerdas yang menggabungkan ilmu teknik autonomous vehicle, geografi, elektronik, dan teknik komputer yang terintegrasi dan dilengkapi dengan fitur yang menggunakan otomatisasi untuk navigasi tanpa input manusia [1]. Autonomous vehicle menggunakan motor listrik industri sebagai pengganti dari motor bakar yang dapat mengurangi polusi udara.

Autonomous vehicle ini dirancang untuk kendaraan yang dapat beroperasi sendiri. Faktor utama dalam mengendarai kendaraan ini adalah faktor keamanan dan keselamatan. Sistem rem merupakan salah satu elemen sangat penting dalam suatu kendaraan. Rem adalah sebuah perangkat pengubah energi dari energi kinetik menjadi energi panas [2] yang dapat berfungsi untuk mengurangi dan atau menghentikan laju kendaraan. Autonomous vehicle yang mempunyai berat dan dapat bergerak dengan kecepatan tertentu akan menghasilkan sebuah energi yaitu energi kinetik. Untuk menghentikan autonomous vehicle tersebut diperlukan energi. Sistem rem pada autonomous vehicle berfungsi mengubah energi kinetik yang menyebabkan autonomous bergerak ke dalam bentuk energi panas.
Jika pada kendaraan konvensional, sistem pengereman dikendalikan oleh pengendara, Namun, pada kendaraan autonomous, sistem pengereman akan bekerja pada keadaan tertentu. Syarat rem yang baik yaitu rem dapat bekerja dengan cepat dan baik, mempunyai daya tahan yang cukup, mudah diperbaiki, dan mudah disetel. Penelitian ini merancang sistem pengereman yang akan bekerja pada keadaan kendaraan yang akan berhenti jika terdapat perintang di depan dan berhenti pada tempat yang telah direncanakan.

Selain itu penelitian ini memodifikasi mekanisme pengereman mekanik yang ada pada kendaraan autonomous dengan aktuator pneumatik silinder. Untuk mekanisme pengereman, input berasal dari sensor warna kamera yang terhubung dengan mikrokontroller yang akan membaca warna tertentu pada area stopping point. Sedangkan mekanisme pengereman untuk menghindari tabrakan, input dan perintahnya berasal dari sensor.

\section{DASAR TEORI}

\subsection{State of the Art}

Penelitian terkait pengontrolan silinder pneumatik melalui mikrokontroller yaitu mengendalikan lengan robot untuk pemisahan barang [3]. Tujuan dari penelitian tersebut adalah mengaplikasikan lengan 
robot untuk proses pemindahan barang yang dapat dipantau dan dikendalikan dari jarak jauh memanfaatkan fasilitas human machine interface. Robot tersebut membutuhkan kontrol sebagai pengatur proses produksi seperti mikrokontroller arduiono uno dan programmable logic control.

Penelitian terdahulu terkait pengujian pengereman pada sarana yaitu penggunaan rem depan pada jarak berhenti becak motor [4]. Penelitian ini memberikan gambaran tentang perhitungan pengereman oleh kedua roda depan becak. Semakin besar gaya tekan pada tuas rem, maka akan semakin besar tekanan hidrolik pada sistem rem cakram yang terdapat pada kedua roda depan becak motor.

Pada perhitungan kebutuhan kompresor dan perhitungan gaya yang keluar dari silinder pneumatik, penulis menggunakan penelitian sistem pneumatik pada mesin pres briket blothong [5]. Penelitian tersebut membahas tentang perencanaan penumatik mulai dari item pneumatik hingga sistem kontrolnya dalam suatu lingkup kerja.

Modul terkait aktuator yang sesuai dengan kebutuhan dalam penelitian ini adalah rangkaian dasar pneumatik [6]. Modul ini membahas tentang komponen kontrol pneumatik yaitu silinder dan katup.
Ada beberapa jenis silinder yaitu silinder kerja tunggal dan kerja ganda.

\subsection{Mobil Listrik Golfcart V6}

Mobil listrik yang akan digunakan dalam penelitian tugas akhir ini adalah golfcart tipe villager 6 . Alasan digunakan nya sarana ini adalah karena bobotnya yang tidak terlalu berat dan mudah untuk dimodifikasi.

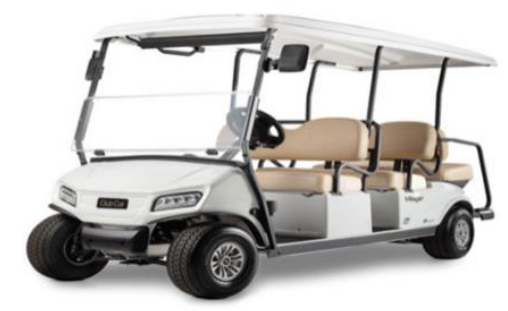

Gambar 1. Mobil golfcart V6

Berikut adalah data spesifikasi golfcart tipe villager 6 :

Tabel 1. Spesifikasi mobil golfcart V6

\begin{tabular}{|l|l|}
\hline Horse Power & $\begin{array}{l}3,7 \mathrm{hp}(2,7) \mathrm{kW} \text {; Rata- } \\
\text { rata }-20 \mathrm{hp}(14,9) \mathrm{kW} ; \\
\text { Peak }\end{array}$ \\
\hline Baterai & $\begin{array}{l}\text { 8-6 V Lead Acid } \\
\text { Speed }\end{array}$ \\
\hline Kmh $16 \mathrm{mph} / 25$ \\
\hline Brakes & Tromol Mekanik \\
\hline Ban & $18 \times 8,50-8$ Tubeless \\
\hline
\end{tabular}




\begin{tabular}{|l|l|}
\hline Body Mobil & $120,1 \mathrm{~cm}$ x $315 \mathrm{~cm}$ \\
\hline $\begin{array}{l}\text { Jarak Sumbu } \\
\text { Roda }\end{array}$ & $250,2 \mathrm{~cm}$ \\
\hline Berat Kosong & $443 \mathrm{~kg}$ \\
\hline Berat Maksimal & $668 \mathrm{~kg}$ \\
\hline
\end{tabular}

\subsection{Rem Tromol}

$\begin{array}{clrr}\text { Rem } & \text { tromol } & \text { adalah } & \text { sistem } \\ \text { pengereman } & \text { pada } & \text { kendaraan } & \text { yang } \\ \text { menggunakan } & \text { gesekan } & \text { antara } & \text { kampas }\end{array}$
dengan sebuah komponen berbentuk mangkuk. Di dalam cover tromol terdapat sepatu rem atau brake shoe. Perbedaan antara rem cakram terdapat pada arah gesekan. Rem cakram memiliki arah gesekan yang saling menjepit atau mendekati sehingga pada rem cakram piringan terdapat ditengah dua kampas. Pada rem tromol, arah gesekan saling menjauh sehingga tromol yang terhubung dengan roda diletakkan di sisi luar dari dua kampas rem.

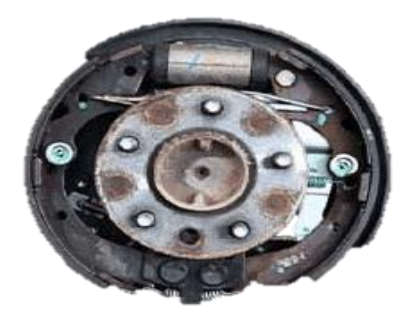

Gambar 2. Rem tromol

\subsection{Pneumatik Silinder}

Pneumatik silinder adalah aktuator yang menggunakan kekuatan udara yang bertekanan untuk menghasilkan kekuatan dalam gerakan bolak balik piston secara linier [7]. Pneumatik silinder dapat digunakan untuk mendorong mesin pemotong, peredam getaran, pintu penyortiran, menjepit benda, dan lain sebagainya. Fungsi dasar pneumatik silinder ini mengkonversi tekanan udara menjadi energi gerak.

Terdapat dua tipe pneumatik silinder yaitu silinder kerja tunggal dan ganda. Silinder kerja tunggal menggunakan kekuatan udara bertekanan untuk mendorong sebuah piston ke dalam satu arah dan untuk mengembalikan piston menggunakan pegas ke posisi semula. Silinder kerja ganda menggunakan udara bertekanan untuk mendorong piston keluar dan mengembalikan ke posisi semula.

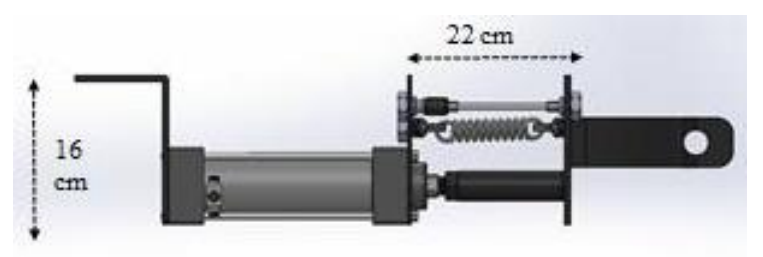

Gambar 3. Pneumatik silinder

Pneumatik silinder akan ditempatkan tepat dibawah return spring. Plat depan terpasang pada bagian belakang lever brake yang berfungsi sebagai pendorong. Plat penahan pneumatik silinder terpasang di sela-sela kabel rem. Penempatan pneumatik silinder yang demikian akan memungkinkan sarana autonomous untuk dioperasikan baik 


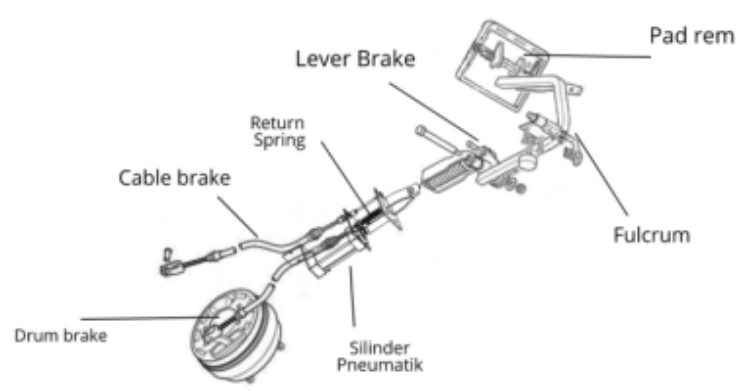

Gambar 4. Letak pneumatik silinder pada sarana

\subsection{Selenoid Valve}

Selenoid valve (katup listrik) adalah katup yang dapat dikendalikan dengan arus listrik AC maupun DC melalui seleonoida atau kumparan [8]. Dalam mengontrol sistem fluida, penggunaan selenoid valve sering digunakan hal tersebut. Selenoid valve berkerja secara elektro mekanik dimana selenoid valve mempunyai kumparan sebagai penggeraknya. Ketika kumparan mendapatkan suplay tegangan baik AC atau DC, maka kumparan akan berubah menjadi medan magnet sehingga dapat menggerakkan piston yang berada di dalamnya.

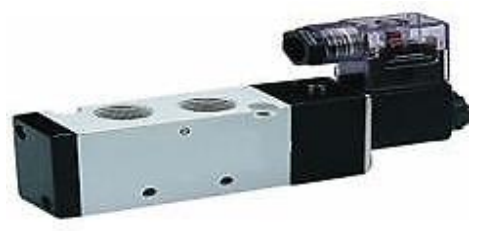

\subsection{Kamera Pixy}

Sensor kamera pixy CMUCam5 ini menggunakan algoritma berbasis warna untuk mendeteksi benda, tracking, dan dilengkapi dengan sensor gambar. Kamera pixy ini memudahkan mikrokontroller dalam proses pembacaan data yang berupa pengolahan citra sehingga dideteksi oleh kamera. Proses pengiriman data pada kamera ke mikrokontroller ini dapat dilakukan dengan jalur komunikasi data diantaranya SPI, I2C, digital out, analog out, dan UART serial.

Kamera ini mempunyai kelebihan yaitu dapat melakukan pengolahan citra yang terintegrasi dan dapat melacak warna tertentu dalam kurun waktu yang bersamaan dengan kecepatan 50 fps (frame per second) tetapi hanya dibatasi dengan tujuh warna yang berbeda.

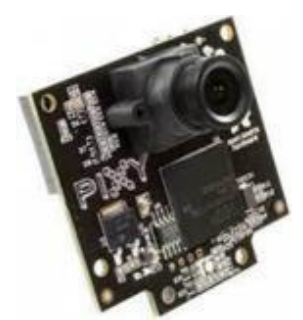

Gambar 6. Kamera pixy CMUCam5 


\subsection{Konsep Kerja Alat}

Sensor micro lidar dan kamera pixy masing-masing terhubung pada pin analog dan berkomunikasi dengan arduiono menggunakan UART (Universal Asynchronous Receiver Transmitter). Board arduino menggunakan catu daya $12 \mathrm{~V}$ yang diturunkan dengan regulator DC ke DC menjadi $5 \mathrm{~V}$ Sedangkan selenoid valve menggunakan catu daya $24 \mathrm{~V}$ yang tertahan oleh high power mosfet switch. Output dari hasil deteksi sensor micro lidar dan kamera pixy akan memberi tegangan sinyal pada mosfet untuk melepaskan tegangan yang tertahan menuju selenoid valve. Output tersebut juga akan men-trigger NO (Normally Open) pada relay menuju sistem kendali motor. Sistem kendali motor disini adalah sebuah controller unit bernama SPM ALTRAX yang berfungsi sebagai pengatur kecepatan pembalik polaritas motor pada sarana.

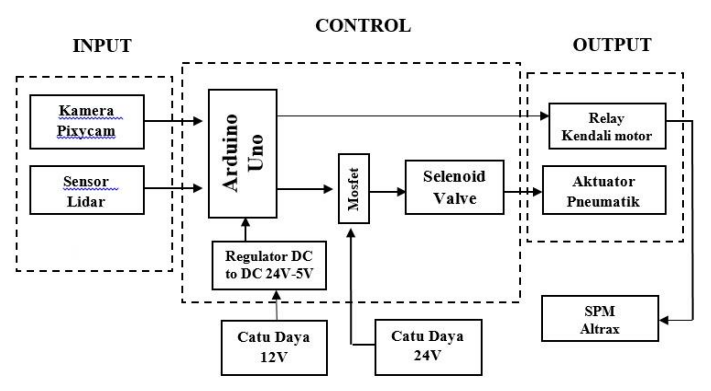

Gambar 7. Konsep kerja alat

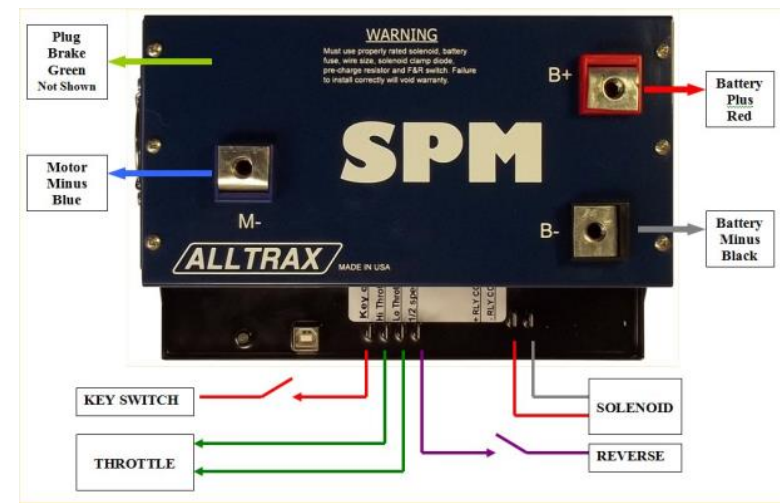

Gambar 8. Controller unit SPM ALLTRAX

\subsection{Sistem Kendali Pengereman}

Sistem kendali pada pengereman sarana autonomous ini menggunakan sistem loop terbuka (open loop). Sistem kendali ini keluarannya tidak berpengaruh pada aksi pengendalian. Keluaran sistem kendali ini tidak diukur atau diumpan-balikan untuk dibandingkan dengan masukan. Set point atau tujuan utama dalam sistem ini adalah menekan pedal rem secara otomatis pada parameter kondisi tertentu. Sensor akan membaca parameter sebagai input yang akan diproses oleh mikrokontroller untuk menjadi output perintah mengaktifkan selenoid valve.

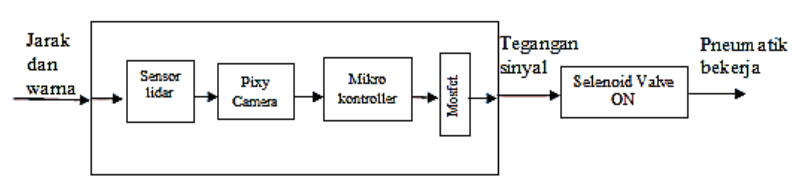

Gambar 9. Alur sistem kendali pengereman 


\section{HASIL DAN DISKUSI}

\subsection{Pemilihan Pneumatik Silinder}

Untuk menentukan kebutuhan pneumatik silinder yang tepat dalam penelitian ini yaitu menghitung gaya perbandingan dari pedal rem (persamaan 1).

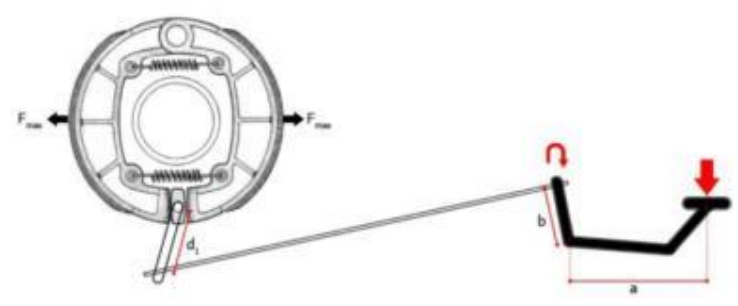

Gambar 10. Gaya pada pedal rem [9]

$K=\frac{a}{b}$

dimana,

$K=$ gaya pada pedal

$a=$ jarak dari pedal rem ke tumpuan

$b=$ jarak dari pushrod ke tumpuan.

Dalam penelitian ini jarak dari pedal ke tumpuan sebesar 40, jarak dari pushrod ke tumpuan sebesar 8 , maka didapatkan gaya pada pedal sebesar 5. Sehingga didapat perbandingan gaya pada pedal rem sebesar 5:1.

Untuk mencari gaya yang dikeluarkan pengendara untuk menekan pedal rem, penulis melakukan percobaan dengan menempatkan batangan rek seberat
$10 \mathrm{~kg}$ pada pedal rem. Dari hasil percobaan tersebut, untuk menarik pedal rem dan mendorong penahan dibutuhkan minimal gaya yang sama seperti yang diberikan batangan rel pada pedal. Dari percobaan tersebut didapatkan bahwa batangan rel seberat $10 \mathrm{~kg}$ mampu menekan pedal rem.

Setelah itu menggunakan persamaan (2) untuk mengetahui gaya yang keluar dari pedal rem [10].

$F K=F \times \frac{a}{b}$

dimana,

$F K$ = gaya yang dihasilkan dari pedal rem (kgf)

$F \quad=$ gaya yang menekan pedal rem (kgf)

$\frac{a}{b}=$ perbandingan tuas pedal rem.

Gaya yang menekan pedal rem sebesar 10kgf, perbandingan tuas pedal rem sebesar 5, maka didapatkan gaya yang dihasilkan dari pedal rem sebesar 50kgf.

Dari percobaan dan perhitungan tersebut, penulis menggunakan pneumatik silinder berukuran 50x50mm dengan diameter psiton sebesar 50mm, dan panjang batang pendorong $50 \mathrm{~mm}$. Berikut adalah gaya piston silinder dari berbagai ukuran pada tekanan 1-10 bar (tabel 1). 
Tabel 2. Indeks kekuatan tekanan pneumatik

\begin{tabular}{|c|c|c|c|c|c|c|c|c|c|c|}
\hline \multirow{3}{*}{$\begin{array}{c}\text { Diameter } \\
\text { Piston } \\
(\mathbf{m m})\end{array}$} & \multicolumn{10}{|c|}{ Tekanan Kerja (bar) } \\
\hline & 1 & 2 & 3 & 4 & 5 & 6 & 7 & 8 & 9 & 10 \\
\hline & \multicolumn{10}{|c|}{ Gaya Piston (kgf) } \\
\hline 6 & 0,2 & 0,4 & 0,6 & 0,8 & 1,0 & 1,2 & 1,4 & 1,6 & 1,8 & 2,0 \\
\hline 12 & 1 & 2 & 3 & 4 & 5 & 6 & 7 & 8 & 9 & 10 \\
\hline 16 & 2 & 4 & 6 & 8 & 10 & 12 & 14 & 16 & 18 & 20 \\
\hline 25 & 4 & 9 & 13 & 17 & 21 & 24 & 30 & 34 & 38 & 42 \\
\hline 35 & 8 & 17 & 26 & 35 & 43 & 52 & 61 & 70 & 78 & 86 \\
\hline 40 & 12 & 24 & 36 & 48 & 60 & 72 & 84 & 96 & 108 & 120 \\
\hline 50 & 17 & 35 & 53 & 71 & 88 & 106 & 124 & 142 & 159 & 176 \\
\hline 70 & 34 & 69 & 104 & 139 & 173 & 208 & 243 & 278 & 312 & 346 \\
\hline 100 & 70 & 141 & 212 & 283 & 353 & 424 & 495 & 566 & 636 & 706 \\
\hline 140 & 138 & 277 & 416 & 555 & 693 & 832 & 971 & 1110 & 1248 & 1386 \\
\hline 200 & 283 & 566 & 850 & 1133 & 1416 & 1700 & 1983 & 2266 & 2550 & 2832 \\
\hline 250 & 433 & 866 & 1300 & 1733 & 2166 & 2600 & 3033 & 3466 & 3800 & 4332 \\
\hline
\end{tabular}

Dari tabel 1, dapat diketahui bahwa pneumatik silinder dengan diameter piston $50 \mathrm{~mm}$ mampu menghasilkan gaya $>50 \mathrm{kgf}$ dengan tekanan kerja 3 bar.

\subsection{Pengujian Alat pada Sarana Berjalan}

Untuk menempatkan pneumatik

silinder sebagai penarik kabel rem, penulis membuat dudukan dari plat besi dengan rancangan menggunakan autocad seperti pada gambar (11).

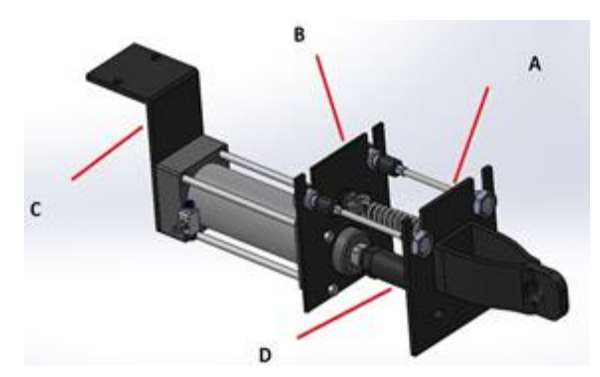

Gambar 11. Desain konstruksi pneumatik silinder

keterangan:
$\mathrm{A}=$ plat pendorong pengait kabel rem
$\mathrm{B}=$ plat penahan pneumatik silinder terhadap kabel rem
$\mathrm{C}=$ plat dudukan yang tertempel pada sarana


$\mathrm{D}=$ as besi untuk menambah panjang bore pneumatik.

Hasil rancangan pada gambar (11) diletakkan dan disesuaikan dengan penempatan ruang kosong yang berada di bawah sarana (gambar 12). Untuk penempatan sensor mini lidar vl5310x, penulis menempatkannya pada bagian depan mobil untuk mendeteksi rintangan (gambar $15)$.

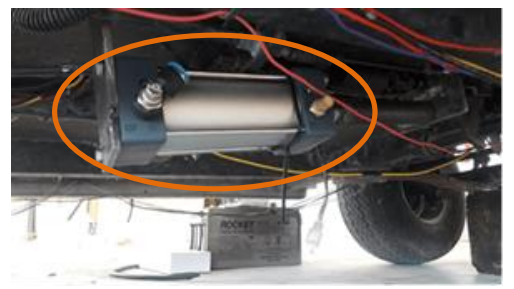

Gambar 12. Penempatan pneumatik

Untuk memastikan bahwa pemasangan alat tidak mengganggu pengoperasian sarana ketika keadaan mengerem normal, penulis melakukan percobaan dengan menginjak pedal rem dan mengamati bagian bawah sarana.

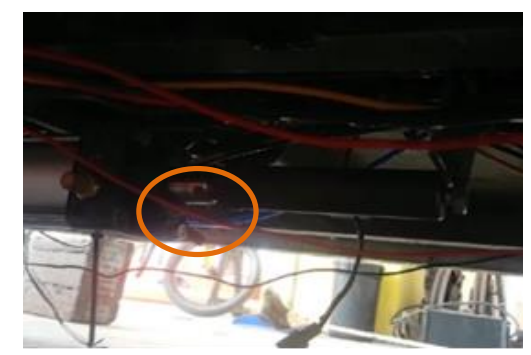

Gambar 13. Posisi pneumatik mengikuti tarikan rem

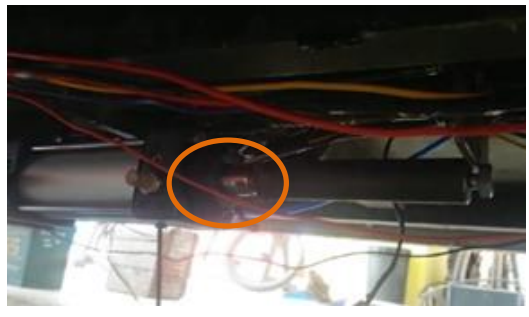

Gambar 14. Posisi penumatik kembali seperti semula

Dari percobaan tersebut didapat bahwa ketika pedal ditarik batang pneumatik akan ikut tertarik bersama penahan kabel rem, dan akan seketika kembali keitka pedal dilepaskan. Maka dapat disimpulkan bahwa pemasangan silinder pneumatik tidak akan mengganggu pengoperasian sarana secara manual.

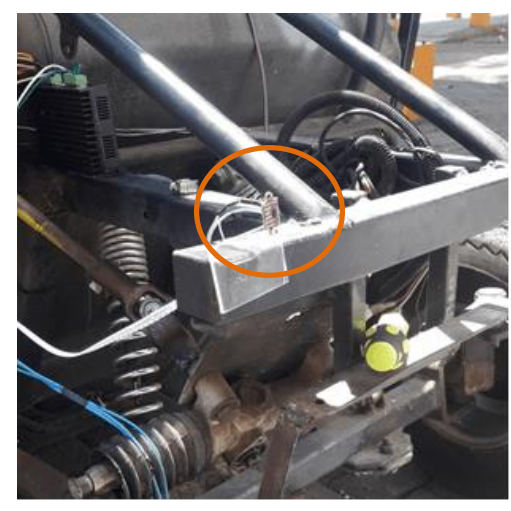

Gambar 15. Letak sensor lidar

Penempatan sensor lidar diperlukan tinggi yang tepat agar pancaran laser dari sensor tidak memantul ke tanah. Untuk mencari tinggi menggunakan persamaan (3). 
$\tan 25^{\circ}=\frac{\text { tinggi }}{\text { jarak maksimal sensor }}$

Jarak maksimal sensor lidar yang digunakan dalam penelitian ini sebesar $200 \mathrm{~cm}$. Dari persamaan (3), diperoleh tinggi sebesar $93 \mathrm{~cm}$ dari permukaan tanah.

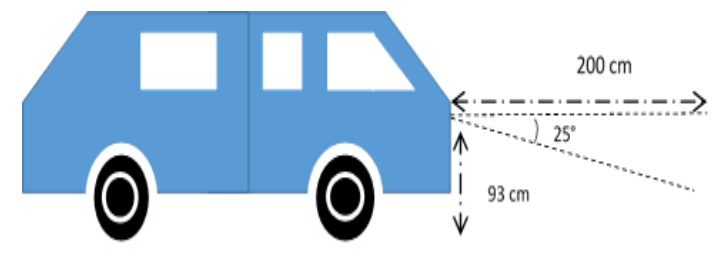

Gambar 16. Sudut pembacaan sensor

Sensor warna pixycam diletakkan di bagian bawah sarana untuk mendeteksi signature colour pada area jalan (gambar 17). Mikrokontroller diletakkan pada bagian depan tempat duduk driver sarana agar lebih mudah dalam mengaktifkan dan menonaktifkannya (gambar 18).

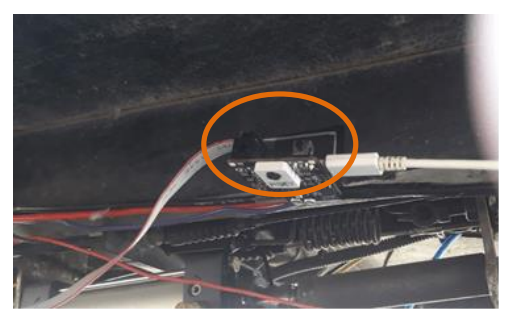

Gambar 17. Letak kamera pixy

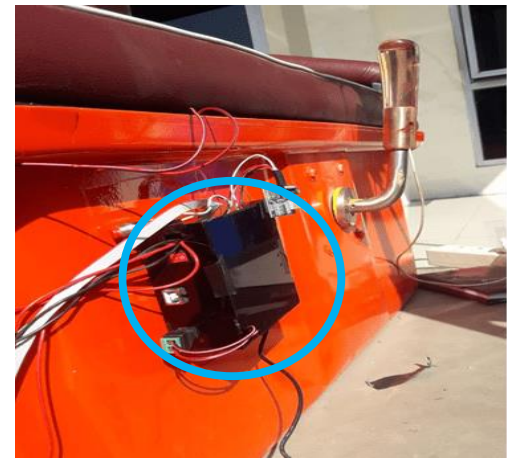

Gambar 18. Letak mikrokontroller

\subsection{Pengujian Alat pada Sarana Berjalan}

Pengujian ini dilakukan untuk mengetahui kinerja alat secara keseluruhan saat sarana dikemudikan. Pengujian dilakukan dengan dua cara yaitu berhenti pada stopping point dan berhenti apabila mendeteksi rintangan.

\subsubsection{Berhenti pada Stopping Point}

Pada kondisi ini, sarana diharapkan berhenti pada marka jalan berwarna yang telah disimpan sebagai signature colour pada pixy camera. Pengujian dilakukan pada kecepatan maksimal 10km/jam dimana driver hanya menginjak pedal gas tanpa menginjak pedal rem. 
Volume 16 Nomor 2 (2021) 1-15

E - Link P-ISSN 1858-2109 E-ISSN 2656-5676

Jurnal Teknik Elektro dan Informatika

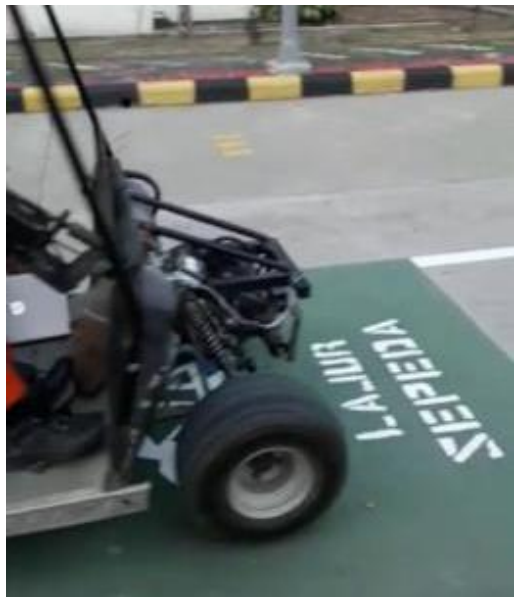

Gambar 19. Sarana berhenti pada marka jalan berwarna

Pengujian dilakukan untuk mengetahui fungsi sensor warna pixycam dalam menangkap marka warna pada jalur dalam kecepatan tertentu. Jarak pengereman pada percobaan ini didapat dengan mengukur selisih letak sarana setelah berhenti total dengan batas warna pada marka jalan.

Dari pengujian tersebut, diperoleh data yaitu dengan beban 1 orang $( \pm 60 \mathrm{~kg})$ dengan kecepatan $10 \mathrm{~km} / \mathrm{jam}$ (tabel 2) dan beban 3 orang $( \pm 180 \mathrm{~kg})$ dengan kecepatan $10 \mathrm{~km} / \mathrm{jam}$ (tabel 3).

Tabel 2. Beban dengan satu orang

\begin{tabular}{cc}
\hline Percobaan & Jarak Pengereman \\
\hline 1 & $178 \mathrm{~cm}$ \\
2 & $169 \mathrm{~cm}$ \\
3 & Tidak berhenti \\
4 & Tidak berhenti \\
\hline
\end{tabular}

\begin{tabular}{cc}
\hline Percobaan & Jarak Pengereman \\
\hline 5 & Tidak berhenti \\
6 & $177 \mathrm{~cm}$ \\
7 & $195 \mathrm{~cm}$ \\
8 & Tidak berhenti \\
9 & Tidak berhenti \\
10 & $188 \mathrm{~cm}$ \\
\hline
\end{tabular}

Tabel 3. Beban dengan tiga orang

\begin{tabular}{cc}
\hline Percobaan & Jarak Pengereman \\
\hline 1 & $212 \mathrm{~cm}$ \\
2 & Tidak berhenti \\
3 & Tidak berhenti \\
4 & $220 \mathrm{~cm}$ \\
5 & $222 \mathrm{~cm}$ \\
6 & Tidak berhenti \\
7 & $220 \mathrm{~cm}$ \\
8 & $224 \mathrm{~cm}$ \\
9 & $222 \mathrm{~cm}$ \\
10 & Tidak berhenti \\
\hline
\end{tabular}

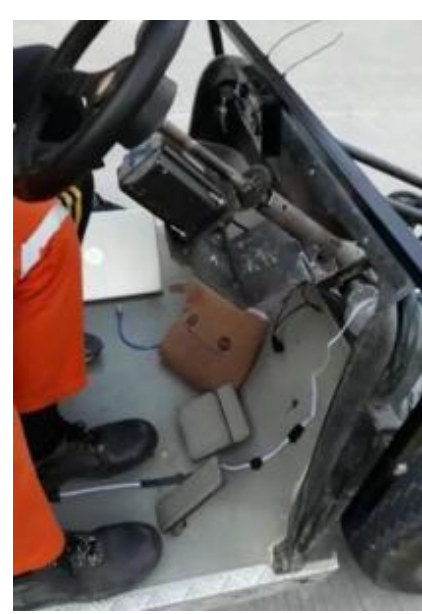

Gambar 20. Pedal rem tertarik ke bawah 
Dari tabel (2) dan tabel (3) tersebut diketahui bahwa jarak pengereman lebih jauh dan masih terdapat sarana belum berhenti setelah melewati marka. Hal ini disebabkan karena respon kamera yang lebih lambat dari sensor mini lidar v15310x. Penggunaan pixycam sebagai pendeteksi marka kurang berfungsi secara maksimal karena kamera mendeteksi warna dengan corak yang mendekati dan kamera tidak bisa menangkap blok warna marka.

\subsubsection{Berhenti Apabila Mendeteksi Rintangan \\ Pada pengujian ini untuk menguji sensor mini lidar pada sarana apabila terdapat rintangan. Pengujian dilakukan dengan kecepatan $10 \mathrm{~km} / \mathrm{jam}$ dimana driver hanya menginjak pedal gas tanpa menginjak pedal rem.}

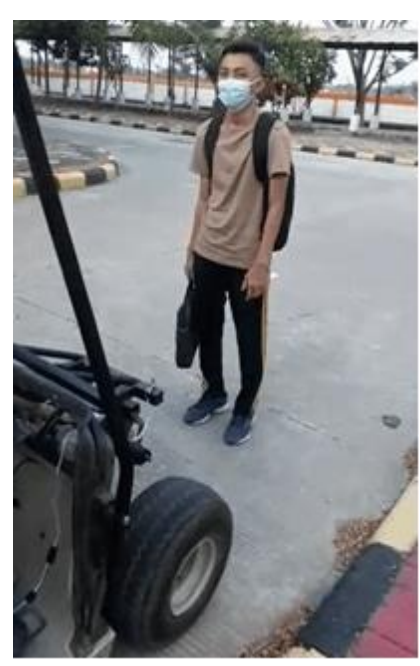

Gambar 21. Pengujian sarana apabila terdapat rintangan

Dari pengujian tersebut, diperoleh data yaitu dengan beban 1 orang $( \pm 60 \mathrm{~kg})$ dengan kecepatan 10km/jam (tabel 4) dan beban 3 orang $( \pm 180 \mathrm{~kg})$ dengan kecepatan $10 \mathrm{~km} /$ jam (tabel 5).

Tabel 4. Beban dengan satu orang

\begin{tabular}{|c|c|c|}
\hline Percobaan & $\begin{array}{c}\text { Jarak dari } \\
\text { Target }\end{array}$ & $\begin{array}{c}\text { Jarak } \\
\text { Pengereman }\end{array}$ \\
\hline 1 & $47 \mathrm{~cm}$ & $143 \mathrm{~cm}$ \\
\hline 2 & $45 \mathrm{~cm}$ & $145 \mathrm{~cm}$ \\
\hline 3 & $45 \mathrm{~cm}$ & $145 \mathrm{~cm}$ \\
\hline 4 & $39 \mathrm{~cm}$ & $151 \mathrm{~cm}$ \\
\hline 5 & $38 \mathrm{~cm}$ & $152 \mathrm{~cm}$ \\
\hline 6 & $32 \mathrm{~cm}$ & $158 \mathrm{~cm}$ \\
\hline 7 & $30 \mathrm{~cm}$ & $160 \mathrm{~cm}$ \\
\hline 8 & $25 \mathrm{~cm}$ & $165 \mathrm{~cm}$ \\
\hline 9 & $25 \mathrm{~cm}$ & $165 \mathrm{~cm}$ \\
\hline 10 & $23 \mathrm{~cm}$ & $167 \mathrm{~cm}$ \\
\hline 11 & $19 \mathrm{~cm}$ & $171 \mathrm{~cm}$ \\
\hline 12 & $11 \mathrm{~cm}$ & $179 \mathrm{~cm}$ \\
\hline 13 & $5 \mathrm{~cm}$ & $185 \mathrm{~cm}$ \\
\hline 14 & $2 \mathrm{~cm}$ & $188 \mathrm{~cm}$ \\
\hline 15 & $\begin{array}{c}\text { Menabrak } \\
\text { target }\end{array}$ & $>200 \mathrm{~cm}$ \\
\hline 16 & $45 \mathrm{~cm}$ & $145 \mathrm{~cm}$ \\
\hline 17 & $44 \mathrm{~cm}$ & $146 \mathrm{~cm}$ \\
\hline 18 & $35 \mathrm{~cm}$ & $155 \mathrm{~cm}$ \\
\hline 19 & $33 \mathrm{~cm}$ & $157 \mathrm{~cm}$ \\
\hline
\end{tabular}




\begin{tabular}{ccc}
\hline Percobaan & $\begin{array}{c}\text { Jarak dari } \\
\text { Target }\end{array}$ & $\begin{array}{c}\text { Jarak } \\
\text { Pengereman }\end{array}$ \\
\hline 20 & $25 \mathrm{~cm}$ & $165 \mathrm{~cm}$ \\
\hline
\end{tabular}

Tabel 5. Beban dengan tiga orang

\begin{tabular}{|c|c|c|}
\hline Percobaan & $\begin{array}{c}\text { Jarak } \\
\text { dari Target }\end{array}$ & $\begin{array}{c}\text { Jarak } \\
\text { pengereman }\end{array}$ \\
\hline 1 & $22 \mathrm{~cm}$ & $168 \mathrm{~cm}$ \\
\hline 2 & $20 \mathrm{~cm}$ & $170 \mathrm{~cm}$ \\
\hline 3 & $22 \mathrm{~cm}$ & $168 \mathrm{~cm}$ \\
\hline 4 & $15 \mathrm{~cm}$ & $175 \mathrm{~cm}$ \\
\hline 5 & $11 \mathrm{~cm}$ & $179 \mathrm{~cm}$ \\
\hline 6 & $12 \mathrm{~cm}$ & $178 \mathrm{~cm}$ \\
\hline 7 & $4 \mathrm{~cm}$ & $186 \mathrm{~cm}$ \\
\hline 8 & $2 \mathrm{~cm}$ & $188 \mathrm{~cm}$ \\
\hline 9 & $\begin{array}{c}\text { Menabrak } \\
\text { target }\end{array}$ & $>200 \mathrm{~cm}$ \\
\hline 10 & $26 \mathrm{~cm}$ & $164 \mathrm{~cm}$ \\
\hline 11 & $26 \mathrm{~cm}$ & $164 \mathrm{~cm}$ \\
\hline 12 & $22 \mathrm{~cm}$ & $168 \mathrm{~cm}$ \\
\hline 13 & $20 \mathrm{~cm}$ & $170 \mathrm{~cm}$ \\
\hline 14 & $19 \mathrm{~cm}$ & $171 \mathrm{~cm}$ \\
\hline 15 & $15 \mathrm{~cm}$ & $175 \mathrm{~cm}$ \\
\hline 16 & $14 \mathrm{~cm}$ & $176 \mathrm{~cm}$ \\
\hline 17 & $11 \mathrm{~cm}$ & $179 \mathrm{~cm}$ \\
\hline 18 & $5 \mathrm{~cm}$ & $185 \mathrm{~cm}$ \\
\hline 19 & $3 \mathrm{~cm}$ & $187 \mathrm{~cm}$ \\
\hline 20 & $2 \mathrm{~cm}$ & $188 \mathrm{~cm}$ \\
\hline 21 & $\begin{array}{c}\text { Menabrak } \\
\text { target }\end{array}$ & $>200 \mathrm{~cm}$ \\
\hline
\end{tabular}

Pengujian dilakukan untuk mengetahui fungsi dari sensor v15310x dalam mendeteksi rintangan dengan kecepatan tertentu. Pada percobaan ini sarana dijalankan pada kecepatan $10 \mathrm{~km} / \mathrm{jam}$ menuju target yang berjarak sekitar 30 meter. Data pada tabel 4 dan tabel 5 menunjukan selisih jarak sarana dari target setelah sarana berhenti total dan jarak pengereman yang diperoleh dari range maksimal pembacaan sensor dikurangi dengan jarak dari target.

Dari data pada tabel 4 dan tabel 5 menunjukan bahwa jarak pengereman semakin jauh seiring beberapa kali percobaan. Hal ini dikarenakan tekanan udara pada air reservoir yang juga berkurang seiring pemakaian. Oleh karena itu, ketika kemampuan dorong pneumatik semakin berkurang yang diindikasikan dengan semakin jauhnya jarak pengereman, air reservoir harus dipompa kembali dangan kompresor. Penambahan beban muatan pada sarana juga dapat mempengaruhi jarak pengereman sarana karena semakin berat beban kendaraan maka jarak tempuh kendaraan akan bertambah di sebabkan oleh kelembaban bergerak [4]. 


\section{KESIMPULAN}

Kesimpulan yang dapat diambil dari penelitian ini adalah sebagai berikut:

1. Pemakaian pneumatik silinder berukuran 50x50mm dengan tekanan kerja 6 bar mampu menarik pedal rem pada sarana autonomous dengan berat kosong sebesar $443 \mathrm{~kg}$ dan berat maksimal sebesar $668 \mathrm{~kg}$;

2. Penggunaan sensor mini lidar vl5310x efektif digunakan untuk mendeteksi rintangan di depan sarana pada kecepatan $10 \mathrm{~km} / \mathrm{jam}$;

3. Penempatan pneumatik silinder menggunakan dudukan yang terbuat dari plat besi yang disesuaikan dengan ruang kosong pada bagian bawah mobil sehingga tidak mengganggu pengereman sarana secara manual.

\section{DAFTAR PUSTAKA}

[1] Y. G. Choi., K. I. Lim., dan J. H. Kim, "Lane Change and Path Planning of Autonomous Vehicle using GIS", The 12th International Conference on Ubiquitous Robots and Ambient Intelligence (URAI 2015), 28-30 Oktober 2015, Goyang City, Korea, pp.163-166.

[2] C. Sutowo., E. Diniardi., S. Yulianto., dan H. Prianto., "Perencanaan Sistem Pengereman Otomatis Sepeda Motor dengan Menggunakan Aktuator Rem
Tromol", SINTEK JURNAL: Jurnal

Ilmiah Teknik Mesin, 3, (1), pp.35-41, (2009).

[3] William., B. Kartadinata, dan L. Wijayanti., "Pengendalian Lengan Robot untuk Proses Pemindahan Barang”, TESLA: Jurnal Teknik Elektro, 21, (1), pp.69-78, (2019).

[4] Zulhaji., Darmawang., M. A. S. Mandra., dan A. Isma., "Jarak Berhenti Becak Motor Dengan Menggunakan Rem Depan”, Prosiding Seminar Nasional LP2M UNM, 31 Agustus-1 September 2019, Makassar, Indonesia, pp.-702-707.

[5] Darto., "Perencanaan dan Simulias Sistem Pneumatik pada Mesin Pres Briket Blothong Berbantuan Perangkat Lunak", Jurnal Teknologi dan Manajemen Informatika (JTMI), 1, (1), pp.5-11.

[6] T. Maryono., "Rangkaian Dasar Pneumatik Komponen Kontrol Pneumatik", Modul Pembelajaran Dasar-Dasar Pneumatik SMKN 2 Sukaharjo, p.63.

[7] S. W. Nasution., Muhaimin., dan S. Azmi., "Rancang Bangun Stempel Otomatis dan Penghitung Produksi Barang Menggunakan Elektro Pneumatik Berbasis Smart Relay SR2B121FU", Jurnal TEKTRO, 3, (1), pp.27-33, (2019). 
[8] R. Shaputra., P. Gunoto., dan M. Irsyam., "Kran Air Otomatis pada Tempat Berwudhu Menggunakan Sensor Ultrasonik Berbasis Arduino Uno”, Sigma Teknika, 2, (2), pp.192-201, (2019).

[9] A. L. Subramanyam., dan S. Banik., "Maximum brake force calculations for Drum Brakes", url: https://www.intentdesign.com/img/pdf/Drum-Brake-

Calculation.pdf, diakses tanggal 06 Agustus 2021.

[10]Qomaruddin., dan T. Hidayat., "Analisa Gaya Sistem Rem Depan Daihatsu Xenia Tipe R Tahun 2012”, Prosiding Seminar Nasional Teknologi dan Informatika, 15 September 2016, Kudus, Indonesia, pp.96-101. 